\title{
Business ecosystem perspective on innovation policy: a case study of San Diego life sciences
}

This is the Author Final Version of paper published in International Journal of Innovation and Learning, 2020 Vol. 27, No.1, pp.19 - 36

\section{Jukka Majava*, Satu Rinkinen**, and Vesa Harmaakorpi ${ }^{\star *}$}

Industrial Engineering and Management

University of Oulu

P.O. Box 4610

FI-90014, Finland

\section{**LUT Lahti}

Lappeenranta University of Technology

Saimaankatu 11

FI-15140, Finland

E-mail: jukka.majava@oulu.fi

E-mail: satu.rinkinen@lut.fi

E-mail: vesa.harmaakorpi@lut.fi

*Corresponding author

\begin{abstract}
This paper applies a business ecosystem perspective to analyse innovation policy. The research utilised a case study on San Diego, which is one of the top three life sciences ecosystems in the world. Unlike previous studies, this research is an analysis of the ecosystem's evolution in each life-cycle phase-birth, expansion, leadership and self-renewal-and the key innovation policy measures related to these phases. The findings indicate that traditional policy measures must be reconsidered in the era of business ecosystems.
\end{abstract}

Keywords: business ecosystem; innovation; innovation policy; learning; life sciences; San Diego

Biographical notes: Dr Jukka Majava is an adjunct professor in industrial engineering and management at the University of Oulu. His industrial experience includes technology marketing, partner and project management, and business development. $\mathrm{He}$ has research interests in innovation and operations management and business networks.

Dr Satu Rinkinen works as a post-doctoral researcher at Lappeenranta University of Technology, LUT Lahti. She works in research projects and her current research interests include innovation policy, innovation systems and regional development.

Dr Vesa Harmaakorpi is professor of innovation systems at Lappeenranta University of Technology, LUT Lahti. Professor Harmaakorpi has a business background. The last eighteen years he has worked within the university community. His research interests are innovation systems and processes as well as innovation environments linked to regional development. 
Author

\section{Introduction}

Because of increasing global competition, many regions seek new growth sectors. Competition also is changing, taking place among business ecosystems that tie together various actors through knowledge flows and shared value creation (Moore, 1993; Iansiti and Levien, 2004). The business ecosystem theory has been claimed as offering more benefits compared with preceding concepts, such as clusters and value chains. These benefits include the capability of providing insights into change dynamics and related strategic consequences (Makinen and Dedehayir, 2012). Although cluster analyses are popular in innovation policy contexts, the cluster concept has been criticised as being unable to explain the underlying factors contributing to certain locations' successes (Kim, 2013). This study aims to provide new insights into innovation policy by applying a business ecosystem perspective to a spatial context. Although business ecosystems span regional boundaries, several ecosystem actors are present locally (Clarysse et al., 2014). Thus, the business ecosystem perspective can provide valuable insights into spatial contexts.

Regardless of increasing competition, especially from Asia, the U.S. remains the global leader in life sciences, with leading locations including the greater Boston area, San Francisco Bay area and San Diego (JLL, 2014). The first two have been studied the most, but interest in San Diego and its unique characteristics recently has increased. For example, San Diego has filed significantly more international patent applications per inhabitant than its rivals (Majava et al., 2016b). Extant research (e.g., Porter, 2001) has examined many factors that have contributed to San Diego's success, including the significance of university, pioneer companies and other institutions, social networks, culture and collaborative learning (Casper, 2007; Walshok and Shragge, 2014; Kim, 2013). Despite the value of the prior research, these previous studies have not applied a business ecosystem perspective in analysing the evolution of the life sciences industry in San Diego and related innovation policy measures. Our study takes a holistic approach in combining the analysis of a business ecosystem evolution through different life-cycle phases, spatial context and innovation policy.

This study extends current knowledge, adopting a business ecosystem approach to analyse San Diego's evolution. The study analyses the spatial ecosystem's evolution in each life-cycle phase: birth, expansion, leadership and self-renewal. The study's objective is to identify issues to consider in innovation policy design and regional industry development, i.e., to examine how policy makers effectively can support development of business ecosystems in a spatial context. The following research questions are used:

1. How has San Diego's life sciences ecosystem evolved, and what innovation policy measures were utilised during each evolutionary phase?

2. How should innovation policy be designed from a business ecosystem perspective?

By addressing these research questions, new knowledge is created on the evolution of a spatial business ecosystem through different life-cycle phases and how innovation policy can support this evolution. Although this study focuses on San Diego life sciences as a specific case, the perspective covers the complete evolution of the ecosystem and related innovation policy measures. The study's major contribution is advancing innovation policy research in a spatial context by offering an analysis of the required measures that could support ecosystem development during different evolutionary phases. In addition, this study provides a novel analysis of the evolution of San Diego's life sciences ecosystem through its life-cycle phases. The paper begins with a review of relevant extant studies on business ecosystems, spatial innovation, and innovation policy. Next, the study's research methodology and findings are 
presented. The paper concludes by highlighting the study's implications, limitations and futureresearch recommendations.

\section{Business ecosystem evolution, spatial innovation and innovation policy}

The business ecosystem concept has become a widely utilised concept when studying, for example, business collaboration and innovation networks (e.g., Rohrbeck et al., 2009; Camarinha-Matos et al., 2009). Innovations - i.e., new products, services and processes/ways of doing things that are commercialised or put into practice - are business ecosystems' central elements and outputs, around which these ecosystems evolve. Business ecosystems are interorganisational value networks comprised of collaborative and competitive relationships among ecosystem firms (Moore, 1993; Autio and Thomas, 2014). Business ecosystem firms deliver integrated solutions to end users as an interrelated system of interdependent companies that combine their skills and assets (Clarysse et al., 2014). Through collaborations in a business ecosystem, these firms can gain a competitive advantage over individual firms (Iansiti and Levien, 2004). In extant literature, the ecosystem lead company's role is highlighted (Iansiti and Levien, 2004), but ecosystem partners are essential in creating a full package of value for customers.

Our study's theoretical starting point lies in a business ecosystem's evolutionary stages. Moore (1993) defined four distinct phases for business ecosystem evolution: birth, expansion, leadership and self-renewal or death. From a collaboration perspective, the key challenge during the birth stage is to work with partners and customers to design a new value proposition based on a seed innovation. The expansion stage, in turn, requires collaborating with partners to scale up supply and attain the largest possible market coverage. During the leadership stage, a compelling future vision is required to encourage partners and customers to continue collaborating and improve the complete offer. Finally, self-renewal necessitates collaborating with innovators to introduce novel ideas into the current ecosystem (Moore, 1993). Moore's approach to ecosystem development and evolution is very firm-based and does not take a position on the policy mix, with the help of which ecosystem development could be supported during different evolutionary phases.

Ecosystems evolve around innovations, and the role of innovation is present during each evolutionary phase, but it is highlighted during the birth and self-renewal phases. Dedehayir et al. (2016) studied the different roles during an innovation ecosystem genesis and categorised them into four groups: leadership roles, direct value-creation roles, value-creation support roles and entrepreneurial-ecosystem roles. Also, they argued that roles can shift from one actor to another during ecosystem emergence (e.g., the ecosystem-leadership role) and that different actors can occupy the same role simultaneously or assume a sequence of different roles during the ecosystem-birth process. During birth, the role of universities and other research organisations is essential. However, their literature-review study focuses only on the birth phase, leaving questions about further evolutionary phases. For example, what is the role of universities and public research funding during the leadership and ecosystem-renewal phases?

The ecosystem concept and the evolution analogy also have been criticised for being mainly metaphorical and providing merely a simplistic explanation of economic and social evolution (Oh et al., 2016). Ritala and Almpanopoulou (2017) respond to this criticism by arguing, based on examples from extant innovation and management studies, that utilising a biology term in another context for academic purposes need not always replicate the original term in detail to be 


\section{Author}

useful. Ritala and Almpanopoulou (2017) also encourage utilising features of ecological and systems thinking to embrace research objects of innovation ecosystem studies more holistically and realistically.

In extant business ecosystem literature, the relevance of place and geographical proximity has not been substantive. Yet, taking an ecosystem approach toward business cooperation and value creation does not change the fact that many ecosystem actors possess a local presence and elicit an effect on the local innovation environment. Business ecosystems characteristically are value networks that cross regional and national boundaries, whereas knowledge or innovation networks typically are clustered and centred geographically around universities and public research organisations (Clarysse et al., 2014). Regional innovation studies that utilise the ecosystem perspective are still a rather new, but growing, strand of literature (e.g., Viitanen, 2016; Radziwon et al., 2016). Proximity and distance (Boschma, 2005), including geographical distance, in innovation activity, learning and network relationships remain relevant despite globalisation. For example, tacit knowledge, which plays a crucial role in innovation processes, contains a regional dimension, as it is often specific to organisational and geographical locations (Reichert, 2006).

Much less has been discussed about business ecosystems in a regional context than, for example, management and technology development. The spatial dimension of ecosystems has been spotlighted in some studies (Viitanen, 2016; Clarysse et al., 2014; Oh et al., 2016), but to help design and manage these ecosystems, more knowledge is needed on spatially defined ecosystems and their success factors, local strengths in global contexts and ecosystem-level processes (Viitanen, 2016). Oh et al. (2016) studied the innovation ecosystem concept in relation to earlier regional innovation focussed concepts - such as science and technology parks, technopoles, regional innovation systems and innovation clusters - and they identified distinguishing features of innovation ecosystems, e.g., a greater appreciation for connections among actors, ICT's central role, open innovation and market forces' greater importance in relation to government push. However, the interest in analysing business and innovation ecosystem concepts alongside or in relation to these regional innovation focussed concepts has grown only recently, with few studies on which to build. By raising regional and spatial perspectives in ecosystem studies, ecosystem research and its results could be connected fruitfully to regional development activities, and the ecosystem perspective can become part of modern regional innovation and development policy.

Innovation policy is an ensemble of goal-directed actions and an allocation of public resources that aim to support creation, commercialisation and diffusion of innovations. Some implications for innovation policy have been presented (e.g., Wessner, 2004; Durst and Poutanen, 2013; Mason and Brown, 2014; Rinkinen and Harmaakorpi, 2017), but more research-based knowledge still is needed on the ways that regional policy actors and authorities can enhance and support creation of successful business ecosystems. Based on the study of knowledge and innovation ecosystems in Belgium, Clarysse et al. (2014) suggested that large companies could be encouraged to play a bigger role in nurturing innovative start-ups and regional ecosystem development. Also, Mason and Brown (2014) found that lead firms' involvement in bottom-up initiatives is important. Clarysse et al. (2014) mentioned public procurement as a possible stimulus to create new ecosystems. They also noted that policy generally has focussed too much on bilateral links and connections, rather than on an ecosystem approach. Based on their innovation ecosystem research, Durst and Poutanen (2013) listed success factors for implementation of innovation ecosystems, e.g., continuous investments in infrastructure, systematic risk assessment, clear role assignment and openness to failure and chaos, which also can be viewed as relevant to innovation policies supporting innovation ecosystem development. 
Title

Mason and Brown (2014) emphasised the need to create different policy approaches for various kinds of ecosystems and to use holistic implementation with these policies.

Rinkinen and Harmaakorpi (2017) studied the business ecosystem concept in relation to three widely used regional innovation policy concepts: clusters, innovation systems and smart specialisation. They identified distinctive characteristics that differentiate business ecosystems from the other three concepts and, therefore, argue that policy-wise, the concept and phenomenon should be examined in a new way. Rinkinen and Harmaakorpi (2017) also called for more empirical research on the innovation policy implications of the business ecosystem concept, as the concept already is used actively in policy-making, although extant research on policy implications, especially in regional contexts, is scant (Rinkinen, 2016). Regional innovation policy development and practice would benefit from empirical research that takes a regional approach to ecosystem development. Ecosystems can be supported by policies that are a blend of top-down and bottom-up policies. Because dynamism and complexity are characteristics of business ecosystems, policy approaches also need to evolve over time and respond to ecosystems' different maturity phases (Mason and Brown, 2014). A vast amount of business ecosystem literature is available from different fields and perspectives, but as the limitations presented above show, connecting the ecosystem perspective to regional and policy contexts may be important, but extant studies have failed to address different policy targets and measures that are essential during different phases of ecosystem evolution. Our study contributes to this research gap between business ecosystems and innovation policy research in a spatial context by identifying issues to consider in innovation policy design and regional development in each of the ecosystemevolution phases.

\section{Methodology}

A case-study research strategy was employed to support an inductive approach in theory building. This study was based on a single in-depth case on San Diego's life sciences business ecosystem, which is considered among the top three in the world, along with the greater Boston area and San Francisco Bay area (JLL, 2014). Utilising a single case enabled us to gain new theoretical insights, as many important studies that have advanced knowledge have been based on a single case (Dyer and Wilkins, 1991). The use of San Diego was deemed appropriate because it offers some unique factors compared with the other two ecosystems (Casper, 2014).

Triangulation (collecting data from multiple sources) is considered important because it enhances case studies' reliability and validity (Voss et al., 2002). Data were collected using (1) researcher observation and notes during six months of field research, (2) analysis of extant studies on San Diego and (3) interviews with key informants comprising 20 individuals who possessed in-depth information on the ecosystem. Snowball sampling was used to choose informants, with all interviews conducted in 2014. Five interviewees represented business, five academia, three incubator and accelerator organisations, three trade organisations, two research institutes and two investors. In addition, many informants served multiple roles in several organisations. Semistructured interviews were used, and the interviews were recorded and transcribed for analysis. The data analysis was conducted using a qualitative approach, with emerging patterns structured into more generic categories that enabled formulation of key concepts and issues. 
Author

\section{San Diego's life sciences ecosystem evolution}

\subsection{Birth}

The San Diego ecosystem can be traced back to the late 19th century. The San Diego region's climate attracted many people with health and respiratory issues. Investment in sanatoriums, hospitals and health-research clinics began in the 1880s (Walshok and Shragge, 2014). The Scripps Institution of Oceanography, funded by the Scripps family, was founded in 1903 as a nonprofit association that the University of California (UC) acquired in 1912 (Walshok and West, 2014).

Three major research institutions were founded in the late 1950s and early 1960s: the Scripps Research Institute, the Salk Institute and UC San Diego (Porter, 2001). Focusing on clean industries was an obvious choice because of limited natural resources and a remote location that prevented the establishment of manufacturing and heavy industries. The aviation industry rose during the 1920s-1940s (Walshok and Shragge, 2014). World War II led to the expansion of the military base and the aircraft industry (Kim, 2013), but creation of the University of California San Diego (UCSD) was the key event that enabled the birth of a successful ecosystem. Before that, the city made zoning decisions that enabled the proximity of various actors: UCSD, research institutes and companies. The city donated land to UC and to polio-vaccine discoverer Jonas Salk's research institute in the late 1950s (Anderson, 1993). In 1971, the city reinforced its plan for a life-sciences research zone, a campus-like environment that would attract talented people and enterprises (Kim, 2013).

A substantial factor that drove UC to create a campus in San Diego in 1960 was the research collaboration between the Scripps Institute of Oceanography and the U.S. Navy (Walshok and Shragge, 2014). The decision also was influenced heavily by the trend toward expanding basic science research and development (R\&D) in the 1950s and 1960s, especially for defence and aerospace applications. However, UCSD had a broader scope, and its strategy was to build excellence in biology, chemistry, math and physics. The strategy included recruiting world-class scientists and researchers (Walshok and West, 2014), which proved to be successful. UCSD's integration of clinical and basic research resembled that of UCSF. The UCSD Medical School, established in 1968, was integrated with basic science departments. A 1,000-bed veterans hospital opened on the campus in 1972 (Casper, 2014).

Two people played key roles in establishing UCSD. Then-California Gov. Edmund Gerald 'Pat' Brown was excited by the idea that any qualified individual could have an elite education through the UC. UCSD was designed to be another Berkeley - excellent, but accessible, unlike private universities. However, recruiting top scientists was difficult because of its lack of a scientific reputation. The scientists who came to the university were risk-takers who were willing to begin something new without the constraints of traditional institutions. A UCSD representative interviewed for this study stated: 'It wasn't that this place hired a bunch of entrepreneurs, but it did hire renegade researchers who wanted to prove they had superior technology, and so that they would partner with entrepreneurs, the investors, to demonstrate the value of their technology'. The second key person was Richard C. Atkinson, UCSD's chancellor from 1980 to 1995. He came out of Stanford University and the National Science Foundation (NSF), and was involved in government programs, specifically the Small Business Innovation Research (SBIR), 
Title

Small Business Technology Transfer Programme (STTR), and Bayh-Dole Act. The SBIR and STTR enabled the NSF and other agencies to fund university-industry research partnerships, whereas the Bayh-Dole Act has been pivotal in technology transfer. Atkinson greatly encouraged UCSD-industry collaborations. According to Moore (1993), this type of collaboration is critical during an ecosystem's birth, expansion and leadership stages.

\subsection{Expansion}

Life sciences' funding increased during the 1970s. Federal government funding - especially from the National Institutes of Health (NIH) and the partnership that comprised UCSD, the Scripps Research Institute and the Salk Institute - increased San Diego's research capacity. The La Jolla Cancer Research Foundation (now the Sanford-Burnham Medical Research Institute) was founded in 1976, and the La Jolla Institute for Allergy and Immunology was founded in 1988. By the mid-1980s, the ecosystem had developed a critical mass of R\&D capacity, attracting international firms and venture-capital investors. Moreover, three pioneer start-ups - Linkabit (wireless), ISSCO (computer graphics) and Hybritech (biotechnology) - played key roles (Kim, 2013; Walshok and Shragge, 2014).

Hybritech was founded in 1978, and its scientist founder, Ivor Royston, a UCSD assistant professor and cancer researcher, saw demand for monoclonal antibodies (Jones, 2005). Monoclonal antibodies can be viewed as the seed innovation (cf. Moore, 1993) around which the ecosystem eventually emerged and began to expand. Hybritech hired people from research institutes and managers with experience in $\mathrm{R} \& \mathrm{D}$, marketing and plant management. Compared with the UCSF-originated Genentech, Hybritech had a very commercial orientation. Several products were launched, and a successful initial public offering (IPO) occurred in 1983 (Casper, 2014; Walcott, 2002). Hybritech's close location to the UCSD campus was convenient for the former academics who worked there, and its success inspired the UCSD and Scripps professors to launch new companies.

However, growth was limited somewhat. Eleven companies were established between 1975 and 1986, and few local venture capitalists existed. Venture-capital (VC) funding was coming from the San Francisco Bay area through syndication. Only Kleiner Perkins actively was supporting creation of new companies (Casper, 2014). Recruiting was difficult because the first start-ups had to lure management talent from outside the region to an emerging, high-risk industry. Conversely, an opportunity existed to build something new in an environment without traditional constraints. Those who were recruited leveraged their personal and professional relationships and brought in additional resources for business, science, capital and business services. The remote location necessitated collaboration and partnering, so sharing resources and contacts became a feature of San Diego's ecosystem (Global Connect, 2010).

Eli Lilly acquired Hybritech for 413 million USD in 1986, Hybritech became a subsidiary of its conservative parent, and many people left the company to become entrepreneurs. Hybritech managers established or assumed senior management positions in tens of firms between 1983 and 1996 (Casper, 2007; Walcott, 2002). The ecosystem benefitted from the experienced, wealthy and high-status networks of managers and scientists. VC firms emerged: Avalon Ventures was founded in 1983, Forward Ventures in 1993 and Kingsbury Capital Partners in 1994 (Casper, 2014). 
Author

Despite Hybritech's initial success, gaps between science and business existed. Capital and IPR competence also were lacking. Reductions in the military sector increased the unemployment rate to 10 percent in 1984. The San Diego Economic Development Corporation contacted UCSD and initiated discussions to encourage more science-business collaborations (Walshok and Shragge, 2014). Local leaders recognised the need to accelerate innovation, and a non-profit intermediary organisation called CONNECT was established in 1985. Preceding that, San Diego lost a bid to Austin, Texas, to attract Microelectronics and Computer Technology Corporation's headquarters. After the loss, a group of local business leaders worked with UCSD Chancellor Richard Atkinson to develop a bottom-up, privately funded, innovation-acceleration program. CONNECT was based at UCSD to ensure that it was perceived as a neutral actor in the ecosystem (Global Connect, 2010).

CONNECT's first CEO, Bill Otterson (a high-tech entrepreneur who sold his business due to cancer), used his contacts to create relationships among entrepreneurs, investors and experts. An advisor interviewed in this study stated:

'Otterson was a very vigorous fellow - he started organising coffees and get-togethers at five o'clock, and it was just really an exchange mechanism for company CEOs particularly who were just getting started. They were all really nascent micro-companies. And they were successful. So, with that form available, that started to draw in venture capitalists. Instead of going around knocking on everybody's door and saying "we need money," they all, I mean CONNECT was the agglomerate of those that were going to be looking for funding. So, it became very important at that time'.

CONNECT does what Otterson started personally; organisation is a key reason behind San Diego's success. Prior to CONNECT, collaboration in vertical industries was modest because companies focussed on their own businesses. CONNECT created trust among the ecosystem's actors (Majava et al., 2016a). CONNECT members shared their contacts to benefit others. Various networking events and lecture series brought different stakeholders together. A local life sciences industry association did not exist yet, but CONNECT's Biotechnology Corporate Partnership Forums attracted interest in San Diego. Large pharmaceutical companies were introduced to small biotech companies to elicit partnerships, supply agreements or even acquisitions. Several large pharmaceutical companies established offices for sales, R\&D and technology-licensing purposes. Afterward, CONNECT's Springboard Programme offered a process for coaching and mentoring entrepreneurs (Global Connect, 2010).

Besides forging collaborations, CONNECT supported the creation of industry organisations. The San Diego Biocommerce Association (BIOCOM) was founded in the early 1990s. Because of severe drought, the city was planning water restrictions, and local biotech companies saw the need to collaborate due to their water dependence. This also led to the city introducing a new business-impact assessment process for its decisions (Global Connect, 2010). CONNECT and BIOCOM were vital in this expansion, as collaboration was needed to scale up the ecosystem (Moore, 1993). 
Title

\subsection{Leadership}

By the mid-1990s, San Diego had developed the world's third-largest biosciences industry, after San Francisco and Boston. Besides UCSD, research institutes such as the Scripps Research Institute and Salk Institute played a major role (Casper, 2014). However, apart from Hybritech and Idec, few large biotech firms were launched in the region. In 1996, approximately 430 life sciences firms existed in San Diego (Walcott, 2002). By 2010, the ecosystem included roughly 500, but only three (Illumina, Amylin Pharmaceuticals and Life Technologies) employed over 1,000 workers (Global Connect, 2010). The life sciences job market in San Diego increased from 7,548 in 1997 to 19,693 in 2002. In 2007, the industry employed 22,719 people (Kim, 2013). Regarding federal R\&D funding, NIH awarded San Diego 919 million USD and the NSF 267 million USD in 2009 (Global Connect, 2010).

The ecosystem developed in a bottom-up way, in that it was self-organised, with a diverse and dense scientific foundation. Cancer, neurosciences and diagnostics research were strong areas, and the importance of genomics and next-generation sequencing increased. The ecosystem operated without a single leader, though CONNECT and BIOCOM's leaders played central roles in providing a joint vision. According to Moore (1993), the leadership stage requires a compelling vision for the future to encourage collaboration. A CEO of a life sciences company interviewed in this study pointed out that 'CONNECT and BIOCOM create the thread, if you will, that tie people together'. However, the life sciences ecosystem differed significantly from the Qualcomm-led wireless ecosystem (Majava et al., 2017), as life sciences lacked a big anchor company, even though Hybritech held that role earlier, and Illumina's influence increased. Various actors contributed to the ecosystem, including universities, research institutes, accelerators, incubators, angel investors, VCs, pharmaceutical companies, incumbent firms, trade organisations, healthcare providers, service providers and local, state and federal governments.

\subsection{Self-renewal}

San Diego is strong in the wireless and life sciences sectors, and their convergence provides an opportunity for the region (JLL, 2014; Walshok and West, 2014). The military sector is still important; counting the ripple effects it accounted for roughly 328,000 (22 percent) of the region's total jobs in 2015 (SDMAC, 2015). Bringing new innovations into the existing ecosystem is critical during the self-renewal phase (Moore, 1993). The ecosystem's development is driven by constant innovation that typically originates from government-funded basic research. Commercialisation is supported by accelerators, technology transfer organisations, incubators, angel investors, venture capitalists, local and external talent pools, and trade organisations. In case of success, an IPO, a merger, or acquisition by another company may occur. Nevertheless, most inventions will not enter the market. Despite failures, constant innovation feeds the local resource pool. People also reinvest in the ecosystem either financially or by spending time mentoring and coaching new entrepreneurs (Majava et al., 2016b).

The ecosystem possesses many strengths, including growth and continuous learning. The convergence between life sciences and wireless provides opportunities in areas such as digital health. Indicators of this convergence include Qualcomm's investments in life sciences and the collaboration between UCSD's schools of medicine and engineering. An investor interviewed in this study stated: 'I think that on the trajectory that we're on now, that it will, it's going to 


\section{Author}

continue to grow and become more robust... there are components of the ecosystem that haven't really worked together very well in the past, and when they start to work together, it's going to build up new strengths, if you will... examples include the collision or the interface between medicine and wireless technology'. Genomics, sequencing and stem cells are also growth areas. For example, genomic data firm Human Longevity recently raised over 220 million USD.

The growth in IPOs and other funding forms (e.g., crowdfunding) bring more capital into the ecosystem, but federal research funding is a concern, requiring research institutes to focus more on commercialisation and public-private partnerships. Pharmaceutical companies also can become more involved in early-stage opportunities. The ecosystem's challenges, such as its remote location, require the local government to commit to development that sustains San Diego's attractiveness (Majava et al., 2016b). The ecosystem's evolution is depicted in Figure 1.

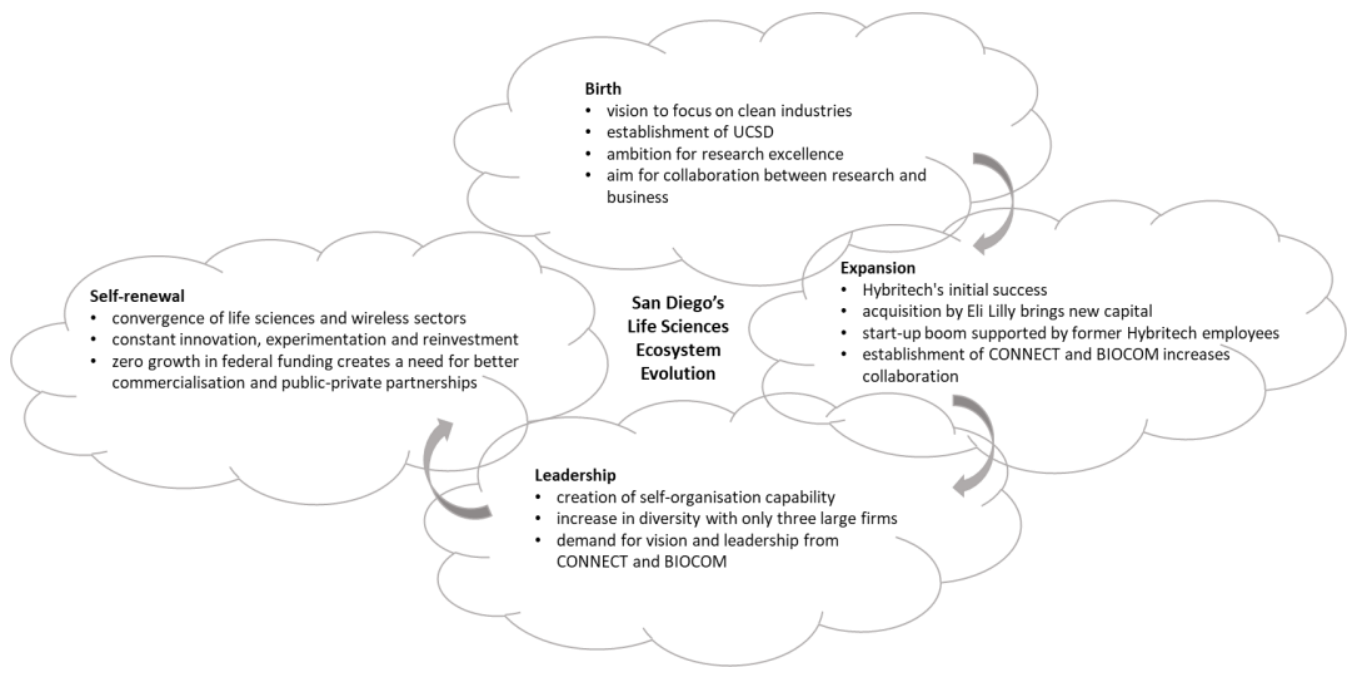

Figure 1. San Diego's life sciences ecosystem evolution

\section{Innovation policy measures: a business ecosystem perspective}

Many researchers have tried to explain San Diego's success. Porter (2001) stressed the importance of educational and research institutions, the capability of attracting federal and state research funding, the local talent pool, the role of local government in fostering a favourable business environment, formal and informal collaborations, and a location and climate that can attract external talent. Walcott (2002) identified the following success factors: a world-class research university, advocacy leadership, risk financing, an entrepreneurial culture and appropriate real estate, combined with an intensive information-exchange network. Jones (2005) and Casper (2007) analysed the social networks and interactions, as well as Hybritech and the start-ups originating from them. A Global Connect report (2010) found that San Diego has benefitted from low entrepreneurial barriers, experience in private-sector-led initiatives, state infrastructure investments, self-organisation capability, federal research-grant acquisition capability, interdisciplinary and entrepreneurial research institutions, strong personal networks, 
Title

proactive engagement with resources and external decision makers, and pioneer companies (e.g., Hybritech). Hwang and Horowitt (2012) claimed that enterprise-friendly policy changes; transparent laws (for real estate, intellectual property, agreements and corporations); low-enough taxes and company-start-up costs; a network of people with experience in technology, science, business and business-related services; and the ability to attract global talent were catalysts for the ecosystem's growth. Kim (2013) stressed the creation of local knowledge and practices, as well as collaborative learning, in the region's success. Walshok and Shragge (2014) argued that San Diego's civic culture is characterised by risk-orientation, entrepreneurial talent, integrative civic platforms and numerous gateways to develop ideas and opportunities and reinvestments. They identified five critical factors: natural advantage of place, early settlers' values, organisation of communities for economic promise, resources and talents that the community cultivated, and how citizens defined and promoted their community.

San Diego's biotech industry emerged from a different university-industry interaction pattern compared with that of San Francisco (Casper, 2014). Typically, a strong pattern of spatial concentration in research organisations, biotech and venture capital exists, but San Diego lacked local venture capital, especially during the 1970s and 1980s. Casper (2014) argued that university-industry collaborations are more common in San Francisco's biotech sector than in San Diego's, with the former's development resonating with broader research in nearby Silicon Valley (e.g., Kenney, 2000). In San Diego, the key networks are entrepreneurial, and they surround a nucleus of commercially oriented managers and scientists with a Hybritech background. This suggests that access to strong entrepreneurial managers early in a company's development can lead to success. Casper (2014) concludes that while a strong science foundation is vital, policies focusing on entrepreneurial-network formation also can cultivate success.

Extant literature and empirical data in this study indicate that several elements of ecosystembased policy apply to San Diego in all developmental phases. These include feeding creativity by developing an attractive, close-proximity environment for entrepreneurs and researchers; maintaining a vivid testing and experimenting culture; generating world-class research capacity; facilitating access to financial and social capital; establishing cooperation networks; and promoting university-industry cooperation. Ecosystem policy is more about orchestrating and facilitating, instead of directly steering or interfering with business. Nevertheless, some elements can be especially important in certain evolutionary phases.

Global Connect (2010) articulated the government's role in the ecosystem's birth. Concrete governmental actions included incentives; tax, regulatory and patent policies; bankruptcy laws; and research and education funding. San Diego benefitted from different governmental actions that often were related, but that started independently. Federal-level activities included private companies' mission-oriented contract work for the U.S. military and other agencies, basic research funding at universities and research institutes, and regulatory processes (e.g., FDA trials). The state provided funding for public universities, including facilities and infrastructure that support research (e.g., UCSD). The local government's land-use decisions in the 1940s and 1950s created the ecosystem's core.

The birth of a spatial business ecosystem requires a common agenda and vision that create an important strategic foundation for other policy-level decisions and actions that affect early development. Committing to common growth and development objectives is a strategy-level 
Author

decision, the effects of which become concrete and visual through, for example, regional and urban planning. San Diego demonstrates the significance of the aforementioned attributes. Creating favourable conditions can start with land use, infrastructure and living-condition-related decisions. In life sciences, the seed of new business often lies in a research-originated idea that can be supported by developing R\&D infrastructure and funding instruments that enable risktaking and radical innovations. Universities and other research institutions can be important platforms, especially for researcher-firm collaborations, providing platforms for spin-offs that can become pioneer companies. The public sector also can provide platforms for testing and piloting (e.g., in hospitals). Public procurements also may foster demand for new innovations.

The Bayh-Dole Act in 1980, establishment of technology-transfer offices and SBIR and STTR programs supported the ecosystem's expansion phase. Key events included Hybritech's unsuccessful acquisition, followed by new start-ups and CONNECT's creation (e.g., Jones, 2005; Casper, 2007). In addition, the local biotech industry self-organised itself because of waterrestriction plans. As for policy, the expansion phase requires tools that support start-up activity and small enterprises' growth. Different funding sources help new businesses develop and grow. Support systems and networks for start-ups, business mentors and incubators are vital. Platforms such as CONNECT can bring different actors together. The leading firm's role is important because it generates growth and attracts a skilled workforce. Removing unnecessary regulations and bureaucracy is of paramount importance as well. A common, strategy-level dedication to growth becomes concrete during expansion.

The ecosystem's leadership phase began during the mid-1990s. Besides research funding from the federal government, the state also played a pivotal role through significant initiatives, such as creation of the California Institutes for Science and Innovation (Cal-ISI) in the early 2000s and the California Institute for Regenerative Medicine (CIRM) in 2005. Regarding ecosystem-oriented innovation policy, successful enterprises' role is stressed during the leadership phase. How should the ecosystem be led to ensure continuous renewal? Yet the ecosystem should operate quite independently without any special policy support. To ensure vitality and continuous renewal, policies should encourage open innovation, cocreation and reinvestment. The leadership phase and preparation for self-renewal also can be supported through long-term research funding.

San Diego's life sciences ecosystem is entering the self-renewal phase. The policy should support the renewal process, instead of old industries and structures that no longer possess future potential. Sotarauta (2005) spoke of self-renewal capacity comprising exploration, integration and leadership, among other attributes. Self-renewal capacity is built during the ecosystem's whole lifespan, but its 'strength' is tested during this phase. The role of radical innovations and new, unexpected combinations again is stressed. Policies that promote interdisciplinarity and diversity are needed, as well as those that promote 'looking for the unknown'. San Diego possesses strengths in different fields. For example, the convergence between life sciences and wireless technology is a very promising path.

Some of the studied ecosystem's unique characteristics should be noted. Actors' proximity (enabled by land-use decisions) is a key differentiator compared with San Francisco and Boston. San Diego's business and academic culture is also very entrepreneurial. The importance of university-industry collaborations was understood during UCSD's creation; the first scientists 
Title

who were recruited voluntarily left well-established universities to pursue their interests. The entrepreneurial culture strengthened through Hybritech and its heirs' success. The local community and decision makers ensured that science and business complemented each other. Numerous intermediary organisations since the 1980s also illustrate this entrepreneurial drive. If a gap is identified in the ecosystem, actors tend to fix it without top-down guidance. Finally, San Diego's relatively small size has fostered a collaborative culture.

\section{Discussion and conclusions}

This study analysed a successful spatial life sciences business ecosystem, its evolution and related innovation policy measures. The results support many of the policy remarks presented in extant studies, including the significance of strong basic research and education, the need to support networking and knowledge exchange, and the need to build infrastructure. The present study contributes to business ecosystem research by offering an innovation policy perspective on business ecosystem evolution, particularly by looking at four different development phases. Its contribution to policy practice also is related to examining ecosystem development through these phases. The evolution and development phase of an ecosystem when planning policy measures can help in targeting policy support and avoiding the creation of unnecessary structures and incentives. Based on this study's findings, we argue that the relevance of policy decisions and support is present throughout the ecosystem life-cycle, but that the role of policy changes with each evolutionary phase.

The results indicate that the birth phase's policy targets are related to basic investments and common vision building. Previous studies highlighted the role of universities and other research organisations as developers and diffusers of new knowledge during the birth phase (Dedehayir et al., 2016). Also, keystone players' role and the possibilities of utilising public-procurement policies as a stimulus for developing new business ecosystems were stressed (Clarysse et al., 2014; Mason and Brown, 2014). Our study supports the notions of a need for basic investments, new knowledge and strong players, but the ability to build strong, forward-looking visions based on which actions are taken also was highlighted in our findings. Some strong individuals (personalities) in the region can enable the birth process. These strong personalities can form a super-creative group if the members focus on the same goal demanding management of attention (Csikszentmihalyi, 1999). To cultivate a competitive vision, an ability to gather future-oriented knowledge is needed. This stresses the importance of regional absorptive capacity in different phases of vision building (cf. Cohen and Levinthal, 1990). A successful birth phase calls for a certain dynamic capability (Pihkala et al., 2007), namely a regional visionary capability (cf. Harmaakorpi and Uotila, 2006) based on absorptive capacity and attention management.

Policy targets during the expansion phase are related to generating start-ups and fostering brokerage functions. To build radically new business concepts, there is often a need to cross distances (e.g., Boschma, 2005). Innovations during the expansion phase often stem from different disciplines, creating the need for intellectual cross-fertilisation and brokering (Parjanen et al., 2010). The objective is to exploit potentials in structural holes of regional networks needing social capital of brokerage (cf. Burt, 2000). Finding these fruitful potentials is often not based on single knowledge bases, but rather on the ability to create combinations and build new worlds 
Author

from existing puzzles (Hintikka, 1988). The necessary capabilities for the expansion phase can be described as a general ability to build possible worlds (Harmaakorpi and Mutanen, 2008).

Based on the study's results, the leadership phase requires support for key value networks and their keystone companies, especially in the form of research funding. This phase often is dangerous because of potential, unnecessary arrogance and lock-ins. Therefore, regional creative tension should be kept (Sotarauta, 1998). Too much bonding through social capital might lead to closeness, requiring leadership capability and bridging social capital (cf. Florida, 2002). A useful capability during the leadership phase is regional leadership capability, including necessary creative social capital. These are interesting results, as extant studies focus on the role of research funding and keystone firms, particularly during the early phases of ecosystem development (Dedehayir et al., 2014; Clarysse et al., 2014). Our results deepen the results from Clarysse et al. (2014), as they suggest that innovation managers at firms within critical industry hubs should recognise their role in business ecosystems and promote collaborations with local innovative start-ups. Our results support this suggestion, but add the notion that such collaborations and cultivation of social capital should happen between industries and other fields, not just within these fields and industries (bonding social capital).

The self-renewal phase's policy targets appear to be related to finding technology adjacencies to find new and feasible ways for new paths. Building related variety platforms might be a useful way to find the most fruitful opportunities for technology adjacencies (Shaughnessy, 2015). Related variety refers to the right kind of distance between industries, knowledge bases and actors in the innovation context. The world's rapid changes make strategies and, for example, technology programs too slow to be tools for regional change. We should rather discuss endogenous restructuring and resilience (Cooke et al., 2012). Therefore, regional self-renewal capacity, including resilience and structural capital, plays a decisive role in the final phase of our assessment. This study's principal findings, combined with earlier knowledge, are presented in Table 1.

Table 1. This study's principal findings

\begin{tabular}{llll}
\hline Phase & Policy focus & 'Soft' policy targets & $\begin{array}{l}\text { Needed capabilities and } \\
\text { capacities }\end{array}$ \\
\hline Birth & Basic investments & Vision building & $\begin{array}{l}\text { Visionary capability } \\
\text { Absorptive capacity }\end{array}$ \\
Expansion & Start-ups & Brokerage functions & $\begin{array}{l}\text { General ability to build } \\
\text { possible worlds }\end{array}$ \\
& & & $\begin{array}{l}\text { Social capital of } \\
\text { brokerage }\end{array}$ \\
Leadership & Key value networks & Creative tension & $\begin{array}{l}\text { Leadership capability } \\
\text { Creative social capital }\end{array}$ \\
& Technology adjacencies & $\begin{array}{l}\text { Related variety } \\
\text { platforms }\end{array}$ & $\begin{array}{l}\text { Self-renewal capacity } \\
\text { Structural capital }\end{array}$ \\
& & & \\
\hline
\end{tabular}


Title

In conclusion, this study's results show that although some policy measures can affect an ecosystem's development throughout its evolution positively, the development phase also can indicate what policy measures are the most effective. San Diego's life sciences ecosystemundoubtedly like most spatial business ecosystems - possesses unique characteristics stemming from local history and culture. From a policy perspective, the right ecosystem policy mix needs to be created by considering these characteristics. Successful spatial business ecosystems and the exact mix of policy measures to support them cannot be duplicated. Thus, supporting such policies requires flexibility in considering the unique characteristics and ability to respond to an ecosystem's evolution. The challenge for policy planning and practice is how to support ecosystem birth, expansion, leadership and renewal without interfering too much with the ecosystem's self-organising and self-renewal dynamics.

As the literature review indicated, some extant studies have examined business ecosystems, as well as policy perspectives, and some observations and results contributing to policy implications of business ecosystem literature have been presented. However, this strand of literature does not discuss policy implications from an ecosystem-evolution perspective, nor does it utilise the linkage to previous regional innovation (policy) literature. As a contribution to extant literature, this study also utilises the soft policy perspective linked with the needed capabilities and capacities during each evolutionary phase.

As managerial implications, we propose utilising soft policy targets alongside more 'traditional' focus, as considering such targets and strengthening needed and related capabilities and capacities can help foster the effects from 'hard' policy support, e.g., investments in infrastructure or low firm-establishment costs. Also, considering both types of policy targets enables the creation of policy mixes that consider the characteristics and evolutionary phases of different business ecosystems in the region. For example, focusing only on basic investments and start-up activities does not necessarily support existing ecosystems' vitality and renewal. We agree with Mason and Brown (2014), who say that a need exists to create different policy approaches for various kinds of business ecosystems and to use holistic implementation. Our study provides elements that can be utilised when building these policy approaches.

Finally, the results presented were based on a single case study, which limits generalisations. A single-case research strategy was deemed the most appropriate because of the opportunity to gain in-depth understanding of the phenomena. For future research, we propose studying other spatial contexts and industry sectors to generate a broader understanding, providing more research that can be compared with the present findings to further validate them.

\section{References}

Anderson, N. S. (1993) An improbable venture: A history of the University of California, San Diego, UCSD Press, San Diego, CA.

Autio, E., and Thomas, L. (2014) 'Innovation ecosystems: Implications for innovation management', in Dodgson, M. Gann, D. M., and Phillips, N. (Eds.), The Oxford handbook of innovation management, Oxford University Press, pp. 204-288.

Boschma, R. (2005) 'Proximity and innovation: A critical assessment', Regional Studies, Vol. 39, No. 1, pp. 61-74. 


\section{Author}

Burt, R. S. (2000) 'The contingent value of social capital', in Lesser, E. L. (ed.), Knowledge and social capital: Foundations and applications, Butterworth-Heinemann, Boston, MA, pp. 255-286.

Camarinha-Matos, L. M., Afsarmanesh, H., Galeano, N., and Molina, A. (2009) 'Collaborative networked organizations-Concepts and practice in manufacturing enterprises', Computers \& Industrial Engineering, Vol. 57, No. 1, pp. 46-60.

Casper, S. (2007) 'How do technology clusters emerge and become sustainable?: Social network formation and inter-firm mobility within the San Diego biotechnology cluster', Research Policy, Vol. 36, No. 4, pp. 438-455.

Casper, S. (2014) 'The University of California and the evolution of the biotechnology industry in San Diego and the San Francisco Bay area', in Kenney, M. and Mowery, D. (Eds.), Public Universities and Regional Growth: Insights from the University of California, Stanford University Press, pp. 66-96.

Csikszentmihalyi, M. (1999) '16 implications of a system perspective for study of creativity', in Sternberg, R. J. (ed.), Handbook of Creativity, Cambridge University Press, New York, NY.

Clarysse, B., Wright, M., Bruneel, J., and Mahajan, A. (2014) 'Creating value in ecosystems: Crossing the chasm between knowledge and business ecosystems', Research Policy, Vol. 43, No. 7, pp. 1164-1176.

Cohen, W. M., and Levinthal, D.A. (1990) 'Absorptive capacity: A new perspective on learning and innovation', Administrative Science Quarterly, Vol. 35, pp. 128-152.

Cooke, P., Parrilli, M., and Curbelo, J. (2012) Innovation, global change and territorial resilience, Edward Elgar Publishing, UK.

Dedehayir, O., Mäkinen, S.J., and Ortt, J.R. (2016) 'Roles during innovation ecosystem genesis: A literature review', Technological Forecasting and Social Change.

Durst, S., and Poutanen, P. (2013) 'Success factors of innovation ecosystems: A literature review', in: Smeds, R., and Irrmann, O. (Eds.) Co-Create 2013: The boundary-crossing conference on co-design in innovation, Aalto University, Espoo, Finland, pp. 16-19.

Dyer, W. G., and Wilkins, A.L. (1991) 'Better stories, not better constructs, to generate better theory: A rejoinder to Eisenhardt', Academy of Management Review, Vol. 16, No. 3, pp. 613-619.

Florida, R. (2002) The rise of creative class. and how it is transforming work, leisure, community and every day life, Basic Books, New York, NY.

Global Connect (2010) Biotechnology cluster project San Diego analysis, USSC, University of Sydney, Australia.

Harmaakorpi, V., and Mutanen, A. (2008) 'Knowledge production in networked practice-based innovation processes-Interrogative model as a methodological approach', Interdisciplinary Journal of Information, Knowledge, and Management, Vol. 3, pp. 87-101.

Harmaakorpi, V., and Uotila, T. (2006) 'Building regional visionary capability. Futures research in resourcebased regional development', Technological Forecasting and Social Change, Vol. 73, No. 7, pp. 778792.

Hintikka, J. (1988) 'What is the logic of experimental inquiry?', Synthese, Vol. 74, No. 2, pp. 173-190.

Hwang, V.W. and Horowitt, G. (2012) The Rainforest: The Secret to Building the Next Silicon Valley, Regenwald, Los Altos Hills, CA.

Iansiti, M. and Levien, R. (2004) 'Strategy as ecology', Harvard Business Review, Vol. 82, No. 3, pp. 68$78+126$.

JLL. (2014) Life Sciences Cluster Report [online] Report, Jones Lang LaSalle, Chicago, Illinois, USA. http://www.jll.com/services/industries/life-sciences/global-cluster-report (Accessed 18 October 2016). 
Title

Jones, M. P. (2005) Biotech's Perfect Climate: The Hybritech Story. PhD Thesis, University of California San Diego.

Kenney, M. (ed.). (2000) Understanding Silicon Valley: The anatomy of an entrepreneurial region, Stanford University Press.

Kim, S. T. (2013) 'Regional advantage of cluster development: A case study of the San Diego biotechnology cluster', European Planning Studies, Vol. 23, No. 2, pp. 238-261.

Majava, J., Kinnunen, T., Foit, D., and Kess, P. (2016a) 'An intermediary as a trust enabler in a spatial business ecosystem', International Journal of Innovation and Learning, Vol. 20, No. 2, pp. 199-213.

Majava, J., Leviäkangas, P., Kinnunen, T., Kess, P., and Foit, D. (2016b) 'Spatial health and life sciences business ecosystem: A case study of San Diego', European Journal of Innovation Management, Vol. 19, No. 1, pp. 26-46.

Majava, J., Kinnunen, T., Foit, D., and Kess, P. (2017). 'Analysing innovation-driven enterprises' stakeholders in two spatial ICT ecosystems', International Journal of Management and Enterprise Development, Vol. 16, No. 3, pp. 207-220.

Mäkinen, S. J. and Dedehayir, O. (2012) 'Business ecosystem evolution and strategic considerations: A literature review', in Proceedings of Engineering, Technology and Innovation (ICE), 18th International ICE Conference, Munich, Germany, 18-20 June 2012, pp. 1-10.

Mason, C., and Brown, R. (2014) Entrepreneurial ecosystems and growth-oriented entrepreneurship [online] https://www.oecd.org/cfe/leed/Entrepreneurial-ecosystems.pdf (Accessed 15 May 2018).

Moore, J.F. (1993) 'Predators and prey: A new ecology of competition', Harvard Business Review, Vol. 71, No. 3, pp. 75-86.

Oh, D. S., Phillips, F. Park, S., and Lee, E. (2016) 'Innovation ecosystems: A critical examination', Technovation, Vol. 54, pp. 1-6.

Parjanen, S., Harmaakorpi, V., and Frantsi, T. (2010) 'Collective creativity and brokerage functions in heavily cross-disciplined innovation processes', Interdisciplinary Journal of Information, Knowledge, and Management, Vol. 5, pp. 1-21.

Pihkala, T., Harmaakorpi, V., and Pekkarinen, S. (2007) 'The role of dynamic capabilities and social capital in breaking socio-institutional inertia in regional development', International Journal of Urban and Regional Research, Vol. 31, No. 4, pp. 836-852.

Porter, M.E. (2001) Clusters of innovation initiative: San Diego [online] Report, Council on Competitiveness, Washington, DC, USA. http://www.compete.org/publications/detail/218/clusters-ofinnovation-initiative-san-diego (Accessed 15 May 2018).

Radziwon, A., Bogers, M., and Bilberg, A. (2016) 'Creating and capturing value in a regional innovation ecosystem: A study of how manufacturing SMEs develop collaborative solutions', International Journal of Technology Management, Vol 75, No. 1-4, pp. 73-96.

Reichert, S. (2006) The rise of knowledge regions: Emerging opportunities and challenges for universities, European University Association.

Rinkinen, S. (2016) Clusters, innovation systems and ecosystems: Studies on innovation policy's concept evolution and approaches for regional renewal, Lappeenranta University of Technology, Lappeenranta, Finland.

Rinkinen, S., and Harmaakorpi, V. (2017) 'The business ecosystem concept in innovation policy context: Building a conceptual framework', Innovation: The European Journal of Social Science Research, Vol. 31, No. 3, pp. 333-349. 


\section{Author}

Ritala, P., and Almpanopoulou, A. (2017) 'In defense of 'eco'in innovation ecosystem', Technovation, Vol. 60, pp. 39-42.

Rohrbeck, R., Hölzle, K., and Gemünden, H.G. (2009) 'Opening up for competitive advantage-How Deutsche Telekom creates an open innovation ecosystem', R\&D Management, Vol. 39, No. 4, pp. 420430.

San Diego Military Advisory Council (2015) San Diego military economic impact study [online] https://www.sdmac.org/impact-study/past-studies/ (Accessed 3 May 2017).

Shaughnessy, H. (2015) Shift: A leader's guide to the platform economy, Tru Publishing, Boise, ID.

Sotarauta, M. (1998) 'Teaching futures seeking communicative policy-processes', American Behavioral Scientist, Vol. 42, No. 3, pp. 449-461.

Sotarauta, M. (2005) 'Tales of resilience from two Finnish cities: Self-renewal capacity in the heart of strategic adaptation', in Duke, C., Osborne, M., and Wilson, B. (Eds.), Rebalancing the social and economic learning, partnership and place, Niace, Leicester.

Viitanen, J. (2016) 'Profiling regional innovation ecosystems as functional collaborative systems: The case of Cambridge', Technology Innovation Management Review, Vol. 6, No. 12, pp. 6-25.

Voss, C., Tsikriktsis, N., and Frohlich, M. (2002) 'Case research in operations management', International Journal of Operations \& Production Management, Vol. 22, No. 2, pp. 195-219.

Walcott, S. M. (2002) 'Analyzing an innovative environment: San Diego as a bioscience beachhead', Economic Development Quarterly, Vol. 16, No. 2, 99-114.

Walshok, M. and Shragge, A. (2014) Invention and Reinvention: The Evolution of San Diego's Innovation Economy, Stanford University Press.

Walshok, M and West, J. (2014) 'Serendipity and symbiosis: UCSD and the local wireless industry', in Kenney, M. and Mowery, D. (Eds.), Public Universities and Regional Growth: Insights from the University of California, Stanford University Press, pp. 127-152.

Wessner, C. W. (2004) Entrepreneurship and the innovation ecosystem policy lessons from the United States, Max Planck Institute for Research into Economic Systems. 